\title{
REVISED Journal editors: How do their editing incomes compare?
}

\section{[version 3; peer review: 2 approved]}

\author{
Janice C. L. Lee (iD) ${ }^{1}$, Jennifer Watt1,2, Diane Kelsall ${ }^{3}$, Sharon E. Straus ${ }^{1,2}$ \\ ${ }^{1}$ University of Toronto, Toronto, Canada \\ 2Unity Health Toronto, Toronto, Canada \\ ${ }^{3}$ CMAJ Open and the CMAJ Group, Ottawa, Canada
}

\begin{tabular}{l}
\hline V3 First published: 24 Aug 2020, 9:1027 \\
https://doi.org/10.12688/f1000research.25620.1 \\
Second version: 18 Jan 2021, 9:1027 \\
https://doi.org/10.12688/f1000research.25620.2 \\
Latest published: 01 Feb 2021, 9:1027 \\
https://doi.org/10.12688/f1000research.25620.3 \\
\hline
\end{tabular}

\section{Abstract}

Background: The work of journal editors is essential to producing high-quality literature, and editing can be a very rewarding career; however, the profession may not be immune to gender pay gaps found in many professions and industries, including academia and clinical medicine. Our study aimed to quantify remuneration for journal editors from core clinical journals, determine if a gender pay gap exists, and assess if there are remuneration differences across publishing models and journal characteristics.

Methods: We completed an online survey of journal editors with substantial editing roles including section editors and editors-in-chief identified from the Abridged Index Medicus "Core Clinical" journals in MEDLINE. We analyzed information on demographics, editing income, and journal characteristics using a multivariable partial proportional odds model for ordinal logistic regression.

Results: There were 166 survey respondents (response rate of 9\%), which represented editors from 69 of 111 journals (62\%). A total of 140 fully completed surveys were analyzed ( 95 males and 45 females); 50 (36\%) editors did not receive remuneration for editorial work. No gender pay gap and no difference in remuneration between editors who worked in subscription-based publishing vs. open access journals were detected. Editors who were not primarily health care providers were more likely to have higher editing incomes (adjusted odds ratio [OR] 2.96, 95\% confidence interval [CI] 1.18-7.46). Editors who worked more than 10 hours per week editing earned more than those who worked 10 hours or less per week (adjusted OR 16.7, 95\%CI 7.0239.76).

Conclusions: We were unable to detect a gender pay gap and a difference in remuneration between editors who worked in subscription-based publishing and those in open access journals. More than one third of editors surveyed from core clinical journals did not get remunerated for their editing work.

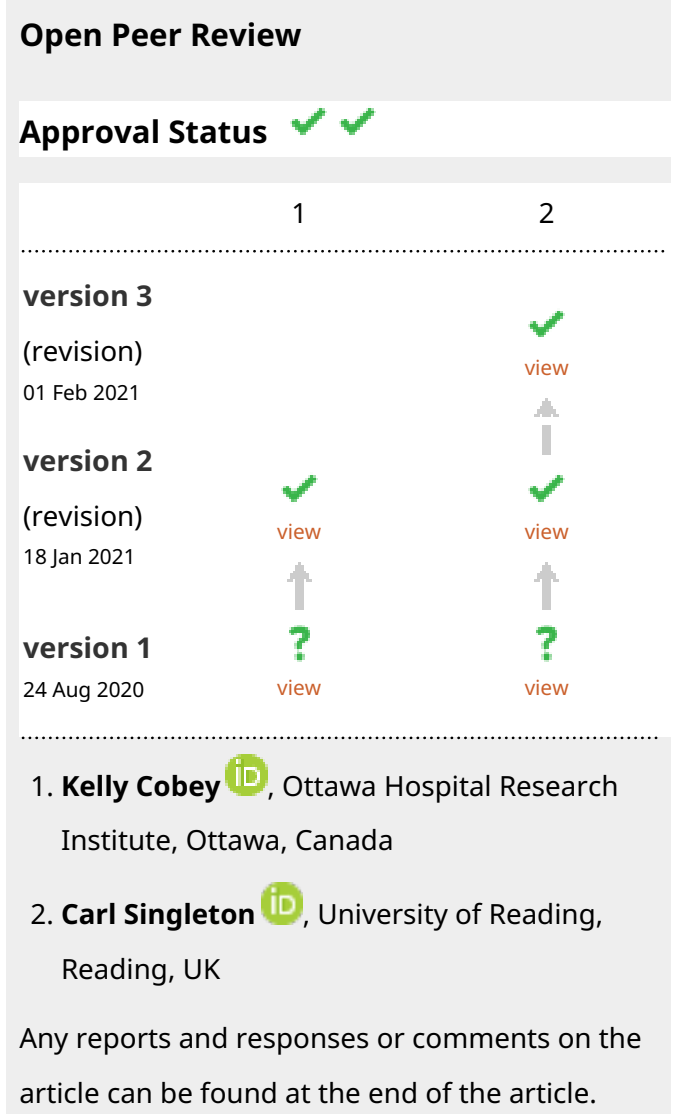


Keywords

Journal, Medical Journalism, Peer review, Publishing, Income

This article is included in the Research on

Research, Policy \& Culture gateway.

Corresponding author: Sharon E. Straus (sharon.straus@utoronto.ca)

Author roles: Lee JCL: Conceptualization, Investigation, Methodology, Writing - Original Draft Preparation; Watt J: Formal Analysis, Methodology, Writing - Review \& Editing; Kelsall D: Conceptualization, Writing - Review \& Editing; Straus SE: Conceptualization, Methodology, Supervision, Writing - Review \& Editing

Competing interests: No competing interests were disclosed.

Grant information: The author(s) declared that no grants were involved in supporting this work.

Copyright: @ 2021 Lee JCL et al. This is an open access article distributed under the terms of the Creative Commons Attribution License, which permits unrestricted use, distribution, and reproduction in any medium, provided the original work is properly cited.

How to cite this article: Lee JCL, Watt J, Kelsall D and Straus SE. Journal editors: How do their editing incomes compare? [version 3; peer review: 2 approved] F1000Research 2021, 9:1027 https://doi.org/10.12688/f1000research.25620.3

First published: 24 Aug 2020, 9:1027 https://doi.org/10.12688/f1000research.25620.1 


\section{REVISED Amendments from Version 2}

Revised to clarify the method of extracting Journal Impact Factor data.

Any further responses from the reviewers can be found at the end of the article

\section{Introduction}

The number of academic journals continues to grow each year. In 2018, there were 5399 clinical journals tracked by Journal Citation Reports in comparison to only 368110 years prior $^{1}$. A rise in open-access journals is also evident; while in 2008 there were just 249 open-access journal titles in Web of Science, that number ballooned to 1431 in $2018^{1}$. Growth in the journal industry comes with more opportunities to become a journal editor. Editors are often scientists, researchers, administrators, and clinicians who have expertise in a particular field and competencies in evaluating articles' suitability for publication in scientific journals ${ }^{2}$. Editorial work can be a very satisfying full-time career or part-time job in addition to a clinical, research, or administrative careers.

Within medicine, substantial evidence of gender inequity in academia exists, including disparities in compensation ${ }^{3-5}$. For example, a 2012 US survey found that male physician researchers had higher average salaries $(\$ 13,399$ USD; $\mathrm{p}=0.001)$ than females after adjusting for specialty, academic rank, and research productivity ${ }^{6}$. Other studies have shown salary deficits can be up to $12-28 \%$ for female physicians ${ }^{7,8}$ when compared to male counterparts. Similar statistics can be found in the UK, where the average pay gap for consultant physicians, including professors, was $13 \%$ in favor of men'. Several countries have mandated pay transparency laws in recent years. Denmark $^{10}$ and Austria ${ }^{11}$ passed laws requiring companies to internally report gender-based wage statistics to it employees in 2006 and 2010 respectively. In 2018, the United Kingdom pushed for national pay transparency and equity by mandating public annual reporting of gender pay gap for any organization comprising more than 250 employees ${ }^{12}$. France followed suit with mandatory reporting, while Germany and Iceland enacted pay equity and transparency laws.

While there is an expanding body of literature on pay gaps in of academia and of medicine in general $^{9,13}$, there is currently very limited literature that evaluates how journal editors are compensated for their work. An international email survey of 88 editors of nursing journals found that their mean annual salary was $\$ 12,749$ USD (ranging from $\$ 0$ to $\$ 56,000$ ) for a mean of 13.4 hours worked per week ${ }^{14}$. A total of $8 \%$ of survey respondents ( 7 of the 88 editors) did not receive any monetary compensation and only $31 \%$ of participants felt that their compensation was adequate ${ }^{14}$. It is concerning that the critical job of editors to uphold the integrity of academic literature can be low-paid or voluntary. With mandatory data reporting, The Lancet reported gender pay gaps of 13-40\% favouring men over women in major UK publishing companies in $2018^{15}$. Specific data for journal editors were not available but some of these data do highlight the potential gaps.

There is substantial heterogeneity among journals, such as publishing platform, scope, publication frequency, and Journal Impact Factor $^{16}$. Though open access publishing comes at a large cost to authors, its popularity is supported by many benefits that may include faster publishing times and the ability to reach bigger audiences compared to subscription-based publishing. It is unknown whether a journal editor's remuneration is affected by these journal variables.

With special interest in biomedical sciences, the objectives of this study were to quantify remuneration for journal editors from core clinical journals, determine if a gender pay gap exists, and assess if there are remuneration differences across publishing models (e.g., subscription-based or open-access) and other journal characteristics (e.g., publication frequency and Journal Impact Factor).

\section{Methods}

Design and participant recruitment

We completed an international online survey of full-time and part-time journal editors identified from the Abridged Index Medicus "Core Clinical" journals in MEDLINE, which represented 111 peer-reviewed core medical journals with high clinical impact. Our target population of journal editors were those with substantial editing roles including editors-in-chief, deputy editors, executive editors, senior editors, associate editors, and editors of a specialty section. Editors were identified through each journal's webpage in December 2018. We excluded roles classified as statistical editors, assistant editors, international editors and editorial board members. If the editors of a section or specialty section numbered greater than 200 for a single journal, these individuals were excluded based on the assumption that they may not have a substantial editorial role. Publicly available emails were found via the English-language search engine, Google. Major sources included journal web pages, academic institutional web pages, and corresponding author on recently published articles. Reporting of this online survey was guided by the CHERRIES reporting guideline $^{17,18}$.

\section{Survey development and pre-testing}

The online survey was conducted using the subscription software, Qualtrics CoreXM Survey Tool ${ }^{19}$. We developed the survey to capture demographic data, editing remuneration in USD, editing experience, and journal characteristics. A blank copy of the survey is available as Extended data ${ }^{18}$. An online pilot test was sent out to our knowledge user team of three journal editors to identify poorly constructed questions, and to assess face validity before distribution. The survey included 10 questions on three pages, and adaptive questioning was used. Respondents were able to review their answers before submission. The following variables were collected in our survey and included in the final multivariable model: sex (male vs. female), gender identity, primary role (health care provider vs. 
other), academic rank (any professorship vs. none), editing role (section/specialty/associate editor vs. editor-in-chief/executive/ senior/deputy editor/other), years in editing ( $>10$ vs. $\leq 10$ years), hours/week in editing role ( $>10$ vs. $\leq 10$ hours), and years worked for current journal ( $>5$ vs. $\leq 5$ years). Journal characteristics of publishing model (subscription-based, vs. open or hybrid [open access option or open access for developing countries]) and frequency of publication (best fitted to monthly/bimonthly vs. weekly/biweekly) were extracted from the journal selected in the survey. A journal's 2017 Journal Impact Factor was obtained from Journal Citation Reports ${ }^{1}$.

\section{Survey administration}

Email invitations with the survey link were distributed via Qualtrics in February 2019. This was a voluntary survey, and no incentives were offered. We employed established methods to enhance survey completion rates with reminder emails at week 2 and week $4^{20}$.

\section{Statistical analysis}

Only completed surveys were analyzed. Dichotomous baseline characteristics for male and female journal editors were presented as frequencies and percentages and compared with the chi-square test or Fisher's exact test when expected sample sizes were 5 or less. Journal Impact Factor of the journal where male and female editors worked was a non-normally distributed continuous variable presented as a median with interquartile range. The Journal Impact Factor of each group was compared with the Wilcoxon rank sum test.

Our outcome of interest was journal editor salary, which was modeled as an ordinal variable with three categories: $\leq \$ 10,000$ per year, $\$ 10,001$ to $\$ 50,000$ per year, and $\geq \$ 50,000$ per year. We derived adjusted odds ratios (OR) and 95\% confidence intervals (CI) for our outcome of interest from a multivariable partial proportional odds model for ordinal logistic regression in SAS version 9.4 (SAS Institute, Cary, North Carolina). The variables for editor sex and academic appointment did not satisfy the proportional odds assumption; therefore, these variables were assumed to have nonproportional odds in the final multivariable partial proportional odds model. Two-sided p-values were reported and p-values $<0.05$ were considered statistically significant.

\section{Ethical approval}

Institutional review board approval was obtained through the Unity Health Toronto Research Ethics Board in Toronto, Canada. The survey landing page included study information and consent to participate was implied by survey completion and submission.

\section{Results}

A total of 2165 editors were identified in December 2018, with 1948 having publicly available email addresses; of these, survey invitations were successfully sent to 1844 without bounce-back. A total of 193 surveys were started, and 166 surveys were submitted (overall response rate of 9\%). We received survey responses from journal editors at 69 of 111 journals (62\%). 140 completed surveys were included in our analyses (Figure 1). Data that had small cell counts $(n<5)$ were not reported to preserve the privacy of participants. A de-identified version of the dataset is available as Underlying data $^{18}$. This was composed of 95 male and 45 female editors. All respondents identified as cis gender. A total of $50(36 \%)$ editors did not receive remuneration for editorial work; 111 (79\%) and $29(21 \%)$ editors worked for a subscription-based journal versus an open/hybrid journal, respectively. A total of $90 \%$ of editors held an academic position. The median 2017 Journal Impact Factor was 4.9 (Interquartile range [IQR] 3.5-6.6 for males and 3.5-7.5 for females). There was a larger proportion of female survey respondents who were fulltime journal editors compared to male counterparts (10 females [22\%] vs. 4 males [4\%] $\mathrm{p}=<0.01)$. Details on baseline characteristics are provided in Table 1.

In univariate analyses (Table 2), journal editors received more remuneration if the journal was open/hybrid access rather than subscription-based (OR 3.06, 95\% CI 1.39-6.75), if the editor was not primarily a health care provider (OR 3.67, 95\% CI 1.7-7.91), if the issues were weekly/biweekly rather than monthly/bimonthly (OR 2.07, 95\% CI 1-4.28), if the editors held senior editing positions (OR 4.5, 95\% CI 2.16-9.59), if the

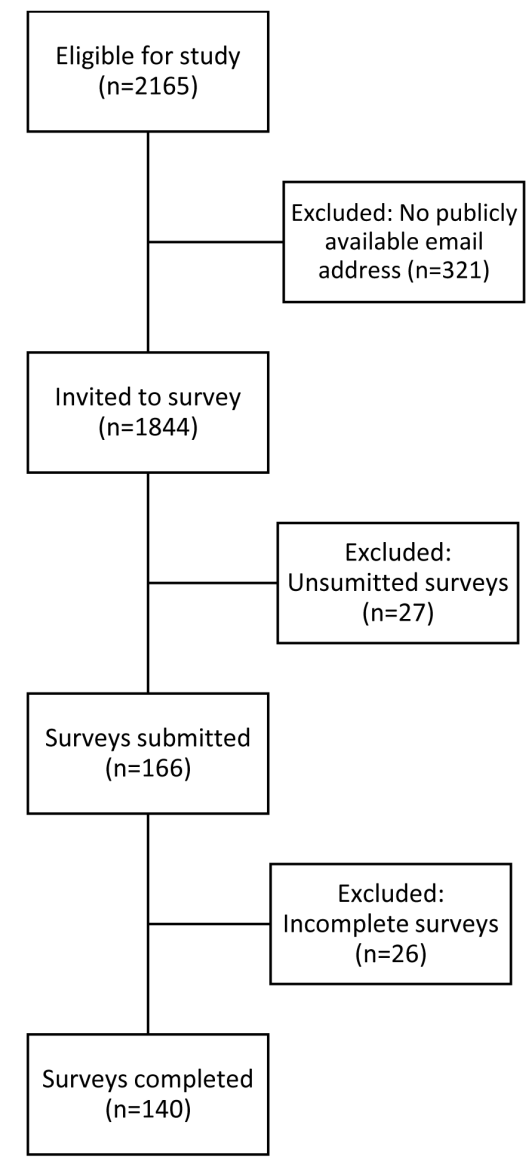

Figure 1. Diagram of study recruitment. 


\begin{tabular}{|c|c|c|c|c|c|}
\hline Characteristic & $\begin{array}{l}\text { Females } \\
(n=45)\end{array}$ & $\begin{array}{l}\% \text { of } \\
\text { Females }\end{array}$ & $\begin{array}{l}\text { Males } \\
(n=95)\end{array}$ & $\begin{array}{l}\% \text { of } \\
\text { Males }\end{array}$ & p-value \\
\hline Annual remuneration in USD, $n$ & & & & & 0.01 \\
\hline$\$ 10000$ or less & 24 & $53.3 \%$ & 67 & $70.5 \%$ & \\
\hline$\$ 10001-50000$ & 7 & $15.6 \%$ & 20 & $21.1 \%$ & \\
\hline Greater than $\$ 50000$ & 14 & $31.1 \%$ & 8 & $8.4 \%$ & \\
\hline Publishing Model, n & & & & & 0.1 \\
\hline Subscription-based & 32 & $71.1 \%$ & 79 & $83.2 \%$ & \\
\hline Hybrid or Open Access & 13 & $28.9 \%$ & 16 & $16.8 \%$ & \\
\hline Primary Role/Occupation, n & & & & & $<0.01$ \\
\hline Health Care Provider & 11 & $24.4 \%$ & 48 & $50.5 \%$ & \\
\hline Other & 34 & $75.6 \%$ & 47 & $49.5 \%$ & \\
\hline Academic Appointment, $n$ & & & & & $0.07^{* *}$ \\
\hline None & 8 & $17.8 \%$ & 6 & $6.3 \%$ & \\
\hline $\begin{array}{l}\text { Assistant, Associate, Full Professor or } \\
\text { Professor Emeritus }\end{array}$ & 37 & $82.2 \%$ & 89 & $93.7 \%$ & \\
\hline \multirow[t]{2}{*}{$\begin{array}{l}2017 \text { Journal Impact Factor, } \\
\text { median (IQR) }\end{array}$} & & & & & $0.53^{* * * *}$ \\
\hline & $4.9(3.5-7.5)$ & & $4.9(3.5-6.6)$ & & \\
\hline Frequency of Publication, $n$ & & & & & 0.21 \\
\hline Monthly or Bimonthly & 29 & $64.4 \%$ & 71 & $74.7 \%$ & \\
\hline Weekly or Biweekly & 16 & $35.6 \%$ & 24 & $25.3 \%$ & \\
\hline Editing Role, $n$ & & & & & 0.26 \\
\hline Section/Specialty/Associate Editor & 30 & $66.7 \%$ & 72 & $75.8 \%$ & \\
\hline $\begin{array}{l}\text { Editor-in-Chief/Executive/ Senior/ } \\
\text { Deputy Editor/Other }\end{array}$ & 15 & $33.3 \%$ & 23 & $24.2 \%$ & \\
\hline $\begin{array}{l}\text { Cumulative Years of Experience } \\
\text { in Editing, } n\end{array}$ & & & & & 0.08 \\
\hline 10 or less & 29 & $64.4 \%$ & 46 & $48.4 \%$ & \\
\hline Greater than 10 & 16 & $35.6 \%$ & 49 & $51.6 \%$ & \\
\hline Hours Spent Per Week Editing, $n$ & & & & & $<0.01$ \\
\hline 10 or less & 27 & $60.0 \%$ & 79 & $83.2 \%$ & \\
\hline Greater than 10 & 18 & $40.0 \%$ & 16 & $16.8 \%$ & \\
\hline Years Employed at the Journal, $n$ & & & & & 0.52 \\
\hline 5 or less & 23 & $51.1 \%$ & 43 & $45.3 \%$ & \\
\hline Greater than 5 & 22 & $48.9 \%$ & 52 & $54.7 \%$ & \\
\hline
\end{tabular}


Table 2. Association between editor characteristics and remuneration.

\begin{tabular}{|c|c|c|}
\hline Characteristics & $\begin{array}{l}\text { Unadjusted OR } \\
(95 \% \mathrm{CI})\end{array}$ & $\begin{array}{l}\text { Adjusted } \\
\text { OR }^{*}(95 \% \mathrm{CI})\end{array}$ \\
\hline Female sex & & $1.39(0.56$ to 3.41$)$ \\
\hline Annual remuneration of greater than $\$ 50000$ USD: Females vs. males & 4.91 (1.88 to 12.83$)$ & \\
\hline Annual remuneration $\$ 10,000$ to $\$ 50,000$ USD: Females vs. males & 2.09 (1.01 to 4.36$)$ & \\
\hline Publishing model: Hybrid or Open Access publishing, vs. Subscription-based & 3.06 (1.39 to 6.75$)$ & 0.83 (0.26 to 2.66$)$ \\
\hline Primary occupation: non-health care provider, vs. health care provider & $3.67(1.7$ to 7.91$)$ & 2.96 (1.18 to 7.46$)$ \\
\hline Academic appointment vs. none & & $0.43(0.1$ to 1.92$)$ \\
\hline Annual remuneration of greater than $\$ 50,000$ USD: Any professorship, vs. none & 0.09 (0.03 to 0.31$)$ & \\
\hline Annual remuneration of $\$ 10,500$ to $\$ 50,000$ USD: Any professorship, vs. none & 0.26 (0.08 to 0.82$)$ & \\
\hline 2017 Journal Impact Factor, median (IQR) & $1.06(1.02$ to 1.11$)$ & 1.02 (0.96 to 1.09$)$ \\
\hline Frequency of Publication: weekly/biweekly, vs. monthly/bimonthly & 2.07 (1 to 4.28$)$ & $1.45(0.51$ to 4.16$)$ \\
\hline $\begin{array}{l}\text { Editing Role: Editor-in-Chief/Executive/Senior/Deputy/Other, vs. Section/ } \\
\text { Specialty/Associate editors }\end{array}$ & 4.5 (2.16 to 9.59$)$ & 1.88 (0.66 to 5.32 ) \\
\hline Cumulative Years of Experience in Editing: greater than 10, vs. 10 or less & 1.96 (0.98 to 3.9) & 1.87 (0.74 to 4.77$)$ \\
\hline Hours Spent Per Week Editing: greater than 10, vs. 10 or less & 16.7 (7.02 to 39.76) & $\begin{array}{l}10.33(3.32 \text { to } \\
32.11)\end{array}$ \\
\hline Years Employed at the Journal: greater than 5, vs. 5 or less & 2.28 (1.13 to 4.62$)$ & $2.22(0.85$ to 5.77$)$ \\
\hline
\end{tabular}

USD = United States dollar. IQR = Interquartile range. CI = Confidence interval. OR = odds ratio. *Adjusted OR for all characteristics in the table.

editors spent more than 10 hours per week editing (OR 16.7, 95\% CI 7.02-39.76), and if the editors had worked for more than 5 years at the journal (OR 2.28, 95\% CI 1.13-4.62).

In multivariable analysis (Table 2), there was no gender pay gap detected or remuneration differences identified between publishing models. We found that editors who were not primarily health care providers were more likely to have higher editing incomes (adjusted OR 2.96, 95\%CI 1.18-7.46). Editors who worked more than 10 hours per week editing earned more than those who worked 10 hours or less per week (adjusted OR 16.7, 95\%CI 7.02-39.76).

\section{Discussion}

In addition to a recent study by The Lancet highlighting the presence of a gender pay gap of employees at major academic publishing companies ${ }^{15}$, numerous studies in the past have highlighted similar inequities across academia ${ }^{3-8}$. In our study of part-time and full-time journal editors from a focused subset of core clinical journals, we did not detect a gender pay gap. We found that annual remuneration for editing was higher for editors working more than 10 hours per week and if their primary occupation was not a health care provider. Full-time journal editing positions were disproportionately more likely to be held by a woman. While we hypothesized that the different revenue structure of subscription-based versus open access journals may translate to a difference in editor's remuneration, we did not find it to be true after adjusting for predictor variables. A journal's Impact Factor did not affect an editor's remuneration. Although $36 \%$ of editors surveyed reported no direct earnings from their editorial work, there can be other benefits including subsidies for scientific meeting registration fees and travel costs.

\section{Limitations}

While there is robust data on gender pay gaps in academia ${ }^{13}$, our study only examined gaps specifically in biomedical sciences. Our study had several limitations. First, our results had limited generalizability due to a low response rate, which can magnify volunteer bias. However, our participants did represent $69 \%$ of the core clinical journals. Moreover, our sample size of 140 was comparable to an international survey of 148 scientific editors from biomedical journals to evaluate journal editing core competencies ${ }^{21}$. We were unfortunately not powered to compare subgroups of editing roles and journal characteristics. Second, given our approach to identifying email addresses for journal editors, our survey was biased towards editors who had either an English-language academic profile on an institutional website or if they were a corresponding author of a recently published article. Third, we were unable to make direct comparisons between for-profit and non-profit journals, because several companies publish journals on behalf of nonprofit organizations. This distinction may factor into a journal editor's desire to edit for a journal at a given remuneration 
rate. In addition, we did not assess non-financial reasons that factor into the decision to be a journal editor. Lastly, there was substantial heterogeneity in editing roles and the lack of standardization in editing titles made it difficult to draw conclusions that were generalizable to the population. Future studies can include qualitative interviews to gauge the various roles and responsibilities of editors, and remuneration practices.

\section{Conclusion}

We conducted an international survey of journal editors from core clinical journals to understand how remuneration varied across editor's demographics, professional experience, and journal characteristics. We did not detect a gender pay gap or a difference in remuneration between editors who worked in subscription-based publishing vs. open access journals. More than a third of editors surveyed were not remunerated for their work.

\section{Data availability}

Underlying data

Harvard Dataverse: Journal editors: How do their editing incomes compare? https://doi.org/10.7910/DVN/AHMB8G ${ }^{18}$.

File 'Journal editors deidentified data.tab' contains a de-identified version of the dataset generated in this study.
Due to the nature of this research, data provided is a limited de-identified dataset without potentially identifying information, i.e. clinical specialty (if applicable) and journal characteristics.

Individual(s) wishing for access to the full de-identified dataset requires written support from the principal investigator (Dr. Sharon Straus, the corresponding author) to be added to the study as study personnel(s), and subsequently needs approval from the Unity Health Toronto Research Ethics Board in Toronto, Canada.

\section{Extended data}

Harvard Dataverse: Journal editors: How do their editing incomes compare? https://doi.org/10.7910/DVN/AHMB8G ${ }^{18}$.

File 'Journal Editors Supplementary 2 - Survey.docx' contains a copy of the survey used in this study.

\section{Reporting guidelines}

Harvard Dataverse: CHERRIES checklist for 'Journal editors: How do their editing incomes compare?'. https://doi.org/10.7910/ DVN/AHMB8G/XPMGJL ${ }^{18}$.

Data are available under the terms of the Creative Commons Zero "No rights reserved" data waiver (CC0 1.0 Public domain dedication)
1. InCites Journal Citation Reports. Clarivate Analytics. 2019. Reference Source

2. Moher D, Galipeau J, Alam S, et al.: Core competencies for scientific editors of biomedical journals: consensus statement. BMC Med. 2017; 15(1): 167. PubMed Abstract | Publisher Full Text | Free Full Text

3. Mascarenhas A, Moore JE, Tricco AC, et al.: Perceptions and experiences of a gender gap at a Canadian research institute and potential strategies to mitigate this gap: a sequential mixed-methods study. CMAJ Open. 2017; 5(1): E144-51.

PubMed Abstract | Publisher Full Text | Free Full Text

4. Paulus JK, Switkowski KM, Allison GM, et al.: Where is the leak in the pipeline? Investigating gender differences in academic promotion at an academic medical centre. Perspect Med Educ. 2016; 5(2): 125-8. PubMed Abstract | Publisher Full Text | Free Full Tex

5. Reed DA, Enders $F$, Lindor $R$, et al: Gender differences in academic productivity and leadership appointments of physicians throughout academic careers. Acad Med. 2011; 86(1): 43-7. PubMed Abstract | Publisher Full Text

6. Jagsi R, Griffith KA, Stewart A, et al:: Gender differences in the salaries of physician researchers. JAMA. 2012; 307(22): 2410-7. PubMed Abstract | Publisher Full Text

7. Asgari MM, Carr PL, Bates CK: Closing the Gender Wage Gap and Achieving Professional Equity in Medicine. JAMA. 2019; 321(17): 1665-1666. PubMed Abstract | Publisher Full Text

8. Henderson MT, Fijalkowski N, Wang SK, et al.: Gender differences in compensation in academic medicine: The results from four neurological specialties within the University of California Healthcare System. Scientometrics. 2014: 100: 297-306. Publisher Full Text

9. Connolly S, Holdcroft A: The pay gap for women in medicine and academic medicine. British Medical Associate Report. 2009. Reference Source

10. Bennedsen M, Simintzi E, Tsoutsoura M, et al.: Do Firms Respond To Gender Pay Gap Transparency? 2019; [Accessed 13 December 2020].

Reference Source
11. National Action Plan on Gender Equality in the Labour Market. Federal Chancellery of Austria. Bundeskanzleramt.gv.at. 2010; [cited 13 December 2020].

Reference Source

12. Gender pay gap reporting: overview. 2017 Reference Source

13. Mumford K, Sechel C: Pay and Job Rank among Academic Economists in the UK: Is Gender Relevant? Br J Ind Relat. 2019; 58(1): 82-113. Publisher Full Text

14. Freda MC, Kearney MH: A first look at nurse editors' compensation. Nurs Econ. 2007; 25(6): 371-275. PubMed Abstract

15. The Lancet: Closing the gender pay gap: when and how? Lancet. 2018; 391(10129): 1455

PubMed Abstract | Publisher Full Text

16. $\mathbf{2 0 1 7}$ Journal Impact Factor. Clarivate Analytics. 2018.

17. Eysenbach G: Improving the quality of web surveys: The Checklist for Reporting Results of Internet E-Surveys (CHERRIES). J Med Internet Res. 2004; 6(3): e34.

PubMed Abstract | Publisher Full Text | Free Full Text

18. Lee JCL, Watt J, Kelsall D, et al.: Journal editors: How do their editing incomes compare? [data set]. Harvard dataverse V1; 2020 [accessed Aug 8, 2020]. http://www.doi.org/10.7910/DVN/AHMB8C

19. CoreXM of Qualtrics. Provo, UT, USA. 2019. Reference Source

20. Dillman DA, Smyth JD, Christian LM: Internet, phone, mail, and mixed-mode surveys: The tailored design method. 4th ed. Hoboken, NJ, US: John Wiley \& Sons Inc. 2014 Reference Source

21. Galipeau J, Cobey K, Barbour V, et al.: An international survey and modified Delphi process revealed editors' perceptions, training needs, and ratings of competency-related statements for the development of core competencies for scientific editors of biomedical journals [version 1; peer review: 2 approved]. F1000Res. 2017; 6: 1634.

PubMed Abstract | Publisher Full Text | Free Full Text 


\section{Open Peer Review}

\section{Current Peer Review Status:}

\section{Version 3}

Reviewer Report 01 February 2021

https://doi.org/10.5256/f1000research.54238.r78579

(C) 2021 Singleton C. This is an open access peer review report distributed under the terms of the Creative Commons Attribution License, which permits unrestricted use, distribution, and reproduction in any medium, provided the original work is properly cited.

\section{Carl Singleton}

Department of Economics, University of Reading, Reading, UK

Amendments are minor and do not change my previous view of "Approving" the article.

Competing Interests: No competing interests were disclosed.

Reviewer Expertise: Labour Economics; Applied Econometrics, including published works on gender in the workplace and the gender pay gap.

I confirm that I have read this submission and believe that I have an appropriate level of expertise to confirm that it is of an acceptable scientific standard.

\section{Version 2}

Reviewer Report 25 January 2021

https://doi.org/10.5256/f1000research.53885.r77562

(C) 2021 Cobey K. This is an open access peer review report distributed under the terms of the Creative Commons Attribution License, which permits unrestricted use, distribution, and reproduction in any medium, provided the original work is properly cited.

\section{Kelly Cobey}

${ }^{1}$ Investigator, Centre for Journalology, Ottawa Hospital Research Institute, Ottawa, ON, Canada

2 Investigator, Centre for Journalology, Ottawa Hospital Research Institute, Ottawa, ON, Canada

The authors have addressed the vast majority of my previous comments in their current version. 
Minor point: The authors state "2017 Journal Impact Factor, and frequency of publication (best fitted to monthly/bimonthly vs. weekly/biweekly), were extracted from the journal selected in the survey."

I would specify where journal impact factor was extracted from - many journals no longer list this information on their website. In these cases was this coded as missing? Or, was the data searched for elsewhere?

Competing Interests: I co-authored a paper with the third author (Diane Kelsall) in Sept 2017. This paper was a team science project with 31 authors. The Centre for Journalology, to which I am a member, has hosted Diane Kelsall to teach on a regularly held 'Introduction to Journalology' course for trainees.

Reviewer Expertise: Journalology; publication science; open science

\section{I confirm that I have read this submission and believe that I have an appropriate level of expertise to confirm that it is of an acceptable scientific standard.}

Author Response 25 Jan 2021

\section{Janice CL Lee}

Re: Journal Impact Factor data.

Thank you for your feedback. The manuscript has been revised to state that Journal Impact Factors were obtained from Journal Citation Reports.

Competing Interests: Diane Kelsall has co-authored a paper with Kelly Cobey in Sept 2017; the paper was a team science project with 31 authors. The Centre for Journalology, to which Kelly Cobey is a member, has hosted Diane Kelsall to teach on a regularly held 'Introduction to Journalology' course for trainees.

Reviewer Report 19 January 2021

https://doi.org/10.5256/f1000research.53885.r77564

(c) 2021 Singleton C. This is an open access peer review report distributed under the terms of the Creative Commons Attribution License, which permits unrestricted use, distribution, and reproduction in any medium, provided the original work is properly cited.

\section{Carl Singleton}

${ }^{1}$ Department of Economics, University of Reading, Reading, UK

2 Department of Economics, University of Reading, Reading, UK

I am satisfied that the authors have taken on board my comments, as far as possible given their current limited access to the data. The authors are also fair and transparent with their methods, assumptions and the potential limitations of the study. 
Competing Interests: No competing interests were disclosed.

Reviewer Expertise: Labour Economics; Applied Econometrics, including published works on gender in the workplace and the gender pay gap.

I confirm that I have read this submission and believe that I have an appropriate level of expertise to confirm that it is of an acceptable scientific standard.

\section{Version 1}

Reviewer Report 11 December 2020

https://doi.org/10.5256/f1000research.28274.r75952

(C) 2020 Singleton C. This is an open access peer review report distributed under the terms of the Creative Commons Attribution License, which permits unrestricted use, distribution, and reproduction in any medium, provided the original work is properly cited.

\section{Carl Singleton}

1 Department of Economics, University of Reading, Reading, UK

2 Department of Economics, University of Reading, Reading, UK

3 Department of Economics, University of Reading, Reading, UK

This study aimed to quantify gender differences in pay for editing services within academia, specifically for "Core Clinical" journals. It also aimed to test for the presence of a gender pay gap, conditional on other observable (surveyed) characteristics of editors and their journals.

Overall, the article is well-written, the methods are clearly explained, and some of the limitations are fairly outlined.

Cobey (2020) has already provided a thoughtful review of this article, and I would echo those comments.

In addition, I would like to make the following further suggestions:

1. In the introduction and the limitations, the authors may wish to dwell on the other reasons that editors choose to do what they do, besides direct financial gain (e.g., enjoyment, prestige, compensation from their main employer in the form of relief from teaching or other activities). These motivations are all potentially endogenous factors (omitted variables) in the regression model. While in theory they may not be correlated with gender in the population of editors, the sample size here is small and the response to the survey probably non-random.

2. The literature cited for the gender pay gap is in academia is limited and very specific, focused on medical sciences. But there are good examples and literature reviews of gender pay gaps in academia more widely. One recent example I am aware of is Mumford \& Sechel 
(2020) ${ }^{1}$ in the British Journal of Industrial Relations. While that study focuses on the gender pay gap among economists, it also provides some prominent examples of the wider literature on the gender gaps in academia, including in Medicine and Science (e.g., Connolly and Holdcroft, $2009^{2}$ ). The authors could look to reference more of this previous work, particularly since this journal is not field-specific.

3. The authors state that "Only completed surveys were analyzed". Elsewhere in the article it is mentioned that responses where editors "preferred not to say" were discarded. Having looked at the survey (Lee et al., 2020), there are some questions asked that are not being used in the analysis. Therefore, the article could be clearer on what information is being thrown away. For instance, for the unadjusted odds ratios, I am not sure why an editor preferring not to say what the frequency of their publication is should exclude them from the sample when estimating the raw gender pay gap. Overall, it is important that the authors explain why they don't consider a larger sample for their statistics just because of some non-response to some survey questions.

4. Like the previous comment, I am also concerned about the amount of information lost in the chosen modelling strategy. The survey collects information on much narrower bands of pay (and hours). While I appreciate that in this field odds models are common and often preferred, in my own field, as an applied economist/econometrician, we would prefer not to lose all the information contained in the pay data collected. For example, I would suggest also estimating a censored linear least squares regression model (i.e., tobit, censored because of the zeroes), where the mid-point of each and every range in the survey is imputed as the pay value, which becomes the dependent variable (normally in natural logs). Similarly, combining the narrow pay bands and narrower hours bands in the survey could allow the authors to look at a measure of hourly pay, which is what matters most economically, being the compensation for a unit of labour input (see Mumford and Smith, $2007^{3}$, for a relevant example of extracting more information from ordinal pay and hours data in this suggested way). Results following this alternative empirical strategy could be presented as a complement to those already shown in the article.

5. In the current ordinal logistic regression model approach, I would be curious what interacting gender with some the other covariates shows. For example, the estimation sample shows a large difference between the male and female in the proportion of editors whose main occupation is Health Care Provider. This variable looks as though it could be worth interacting with gender. This could be added as a third column of results in Table 2 . Minor comment:

1. The Introduction claims that the UK led the wag on gender pay gap reporting legislation. Denmark and Austria have legislation requiring firms to make their pay gaps available to their workers, which I believe substantially pre-date the UK policy (2006 in Denmark; see Bennedsen et al., 2019²).

\section{References}

1. Mumford K, Sechel C: Pay and Job Rank among Academic Economists in the UK: Is Gender Relevant?. British Journal of Industrial Relations. 2020; 58 (1): 82-113 Publisher Full Text

2. Connolly S, Holdcroft A: The pay gap for women in medicine and academic medicine. 2009. 3. MUMFORD K, SMITH P: THE GENDER EARNINGS GAP IN BRITAIN: INCLUDING THE WORKPLACE. 
The Manchester School. 2007; 75 (6): 653-672 Publisher Full Text

4. Bennedsen M, Simintzi E, Tsoutsoura M, Wolfenzon D: Do Firms Respond to Gender Pay Gap

Transparency?. 2019. Publisher Full Text

Is the work clearly and accurately presented and does it cite the current literature?

Yes

Is the study design appropriate and is the work technically sound?

Partly

Are sufficient details of methods and analysis provided to allow replication by others? Yes

If applicable, is the statistical analysis and its interpretation appropriate?

Yes

Are all the source data underlying the results available to ensure full reproducibility? Yes

Are the conclusions drawn adequately supported by the results? Partly

Competing Interests: No competing interests were disclosed.

Reviewer Expertise: Labour Economics; Applied Econometrics, including published works on gender in the workplace and the gender pay gap.

I confirm that I have read this submission and believe that I have an appropriate level of expertise to confirm that it is of an acceptable scientific standard, however I have significant reservations, as outlined above.

Author Response 10 Jan 2021

Janice CL Lee

Re: \#1) Thank you. Revised to address this limitation in both the introduction and limitations sections.

Re: \#2) Thank you. This was added to the limitations section. Mumford \& Sechels 2020 and Connolly and Hodcroft 2009 were cited.

Re: \#3) Thank you. This was clarified in the manuscript. Of the 166 surveys, 140 were analyzed, excluding surveys that had incomplete responses. Responses of "prefer not to answer" were analyzed but often had small cell counts $(n<5)$, and therefore the data were not reported to preserve privacy of participants.

Re: \#4) We did not perform the tobit regression, since we did not have exact salaries and 
cannot make an assumption regarding the mid-point values for the last category of salaries greater than $\$ 150,000$ USD. In analyzing the zero/nonzero pay by male/female to explore censoring from the zeros, we found the following:

chi-squared $1.35(p=0.25)$

2x2 table:

Zero salary, male: 37

Zero salary, female: 13

Nonzero salary, male: 58

Nonzero salary, female: 32

This analysis has not been included in the article.

Re: \#5) We presented the data based on male/female as primary exposure and did not examine for possible interaction of gender with covariates. We are unable to return to the data at this time to update the analysis to explore this possibility.

Re: Minor \#1) Thank you. This has been revised to add Denmark and Austria's reporting legislation.

Competing Interests: None.

Reviewer Report 27 October 2020

https://doi.org/10.5256/f1000research.28274.r72508

(C) 2020 Cobey K. This is an open access peer review report distributed under the terms of the Creative Commons Attribution License, which permits unrestricted use, distribution, and reproduction in any medium, provided the original work is properly cited.

\section{Kelly Cobey}

${ }^{1}$ Investigator, Centre for Journalology, Ottawa Hospital Research Institute, Ottawa, ON, Canada

2 Investigator, Centre for Journalology, Ottawa Hospital Research Institute, Ottawa, ON, Canada

${ }^{3}$ Investigator, Centre for Journalology, Ottawa Hospital Research Institute, Ottawa, ON, Canada

This study aimed to:

1. quantify remuneration for journal editors from core clinical journals

2. determine if a gender pay gap exists

3. assess if there are remuneration differences across publishing models and journal characteristics.

The authors addressed these aims through conducting an online survey of journal editors identified from the Abridged Index Medicus "Core Clinical" journals in MEDLINE.

The paper is reported clearly and acknowledges relevant limitations. I describe a few suggestions for changes below:

The authors specify: 
"The following variables were collected in our survey and included in the final multivariable model: sex (male vs. female), gender identity, publishing model (subscription-based, vs. open or hybrid [open access option or open access for developing countries]), primary role (health care provider vs. other), academic rank (any professorship vs. none), 2017 Journal Impact Factor, frequency of publication (monthly/ bimonthly vs. weekly/biweekly), editing role (section/specialty/ associate editor vs. editor-inchief/executive/senior/deputy editor/other), years in editing (>10 vs. $\leq 10$ years), hours/week in editing role (>10 vs. $\leq 10$ hours), and years worked for current journal ( $>5 \mathrm{vs.} \leq 5$ years)."

When I review the survey provided by the authors, I don't see any items asking about the 2017 journal impact factor or journal frequency of publication. Perhaps I missed something? If not, this leads me to think that perhaps the authors extracted this information online based on participants responses indicating which journal they are an editor at, or that the incorrect survey has been uploaded. This should be clarified in the paper.

Further, the authors indicate the survey captured the frequency at which the included editors' journals publish using the options: monthly/ bimonthly vs. weekly/biweekly. This is unlikely to apply uniformly across journals. For illustration, I don't know how the F1000 journal editor would accurately respond to this item.

Did the authors record bounce-backs among editors who they e-mailed their invitation to? In comparable work I have conducted this has been a fairly significant issue, especially when editor information is found via Google rather than through the journal website. If so, what was the $\mathrm{N}$ and could this be reflected in the study recruitment description and figure? The response rate may be somewhat higher if this is considered.

Minor comments:

Given that this is not a sub-specialty journal, the authors could consider briefly addressing what the role and responsibilities of journal editors are in the introduction.

The authors note: "The online survey was conducted using Qualtrics CoreXM Survey Tool software14, but an open access alternative such as SurveyMonkey15 could be used for replication of methods. ; I don't think the free SurveyMonkey would be appropriate for replicating the survey described, I understand it allows for only 10 questions (each sub question 'counts') and 100 responses.

The authors could provide rational for the journal sampling approach.

Is the work clearly and accurately presented and does it cite the current literature? Yes

Is the study design appropriate and is the work technically sound?

Yes

Are sufficient details of methods and analysis provided to allow replication by others? Partly

If applicable, is the statistical analysis and its interpretation appropriate? Yes

Are all the source data underlying the results available to ensure full reproducibility? 
Yes

Are the conclusions drawn adequately supported by the results?

Yes

Competing Interests: I co-authored a paper with the third author (Diane Kelsall) in Sept 2017. This paper was a team science project with 31 authors. The Centre for Journalology, to which I am a member, has hosted Diane Kelsall to teach on a regularly held 'Introduction to Journalology' course for trainees.

Reviewer Expertise: Journalology; publication science; open science

I confirm that I have read this submission and believe that I have an appropriate level of expertise to confirm that it is of an acceptable scientific standard, however I have significant reservations, as outlined above.

Author Response 10 Jan 2021

\section{Janice CL Lee}

Re: Extracting journal information--Yes, revised to state that journal information was extracted online based on journal selection in the survey.

Re: Journal frequency-Journal frequency was extracted from journals and rounded up/down to fit the categories.

Re: Bounce-back emails-Yes, revised to clarify that there were 104 bounce-backs. The response rate was calculated based on the number of successful emails sent.

Re: Minor comment on role of journal editors-Thank you, this has been added to the introduction.

Re: Minor comment on free survey software-Thank you, this has been removed. To our knowledge, there are no easily accessible free survey software for survey replication.

Re: Minor comment on the rational for journal sampling-Revised to state that we chose the core clinical journal for their high clinical impact on medicine.

Competing Interests: None. 
The benefits of publishing with F1000Research:

- Your article is published within days, with no editorial bias

- You can publish traditional articles, null/negative results, case reports, data notes and more

- The peer review process is transparent and collaborative

- Your article is indexed in PubMed after passing peer review

- Dedicated customer support at every stage

For pre-submission enquiries, contact research@f1000.com 